\title{
Correction to: Multi-Solvent Microdroplet Evaporation: Modeling and Measurement of Spray-Drying Kinetics with Inhalable Pharmaceutics
}

Mani Ordoubadi ' Florence K. A. Gregson ${ }^{2}$ - Omar Melhem ' • David Barona ' Rachael E. H. Miles ${ }^{2}$ - Dexter D'Sa ${ }^{3}$ - Sandra Gracin ${ }^{4}$. David Lechuga-Ballesteros ${ }^{3} \cdot$ Jonathan P. Reid ${ }^{2} \cdot$ Warren H. Finlay $^{\prime} \cdot$ Reinhard Vehring '

Published online: 29 May 2019

(C) Springer Science+Business Media, LLC, part of Springer Nature 2019

\section{Correction to: Pharm Res https://doi.org/ I0.1007/s I 1095-019-2630-7}

The Publisher regrets having introduced the following errors into the article when performing proof corrections:

1. the equation immediately above equation 19: has a red "p" instead of the greek letter "pi", and the mdot_i has two dots instead of one and the "i" is under the character instead of being its subscript

2. the equation immediately after equation 19: has the same problems with the letter "pi" and mdot_i

3. equation 21: has the same problem with mdot_i and also the right square bracket is smaller than the left one

The original article has been corrected.

Publisher's Note Springer Nature remains neutral with regard to jurisdictional claims in published maps and institutional affiliations.

The online version of the original article can be found at https://doi.org/l 0 . | 007/s | | 095-0| 9-2630-7

Reinhard Vehring

reinhard.vehring@ualberta.ca

Department of Mechanical Engineering, University of Alberta, Edmonton, Alberta, Canada

2 School of Chemistry, University of Bristol, Bristol, UK

3 Pharmaceutical Technology \& Development, AstraZeneca R\&D South San Francisco, San Francisco, California, USA

4 Pharmaceutical Technology \& Development, AstraZeneca R\&D

Gothenburg, Gothenburg, Sweden 